\title{
Urodimento
}

REVISTA DE ESTUDOS EM ARTES CÊNICAS

E-ISSN 2358.6958

\section{As reverberações de Pega Teatro, de Joana Lopes: Contribuições para uma pesquisa em teatro educação}

Theda Cabrera

Francisco Souza da Silva

Para citar este artigo:

CABRERA, Theda; SILVA, Francisco Souza da. As reverberações de Pega Teatro, de Joana Lopes: Contribuições para uma pesquisa em teatro educação. Urdimento - Revista de Estudos em Artes Cênicas, Florianópolis, v. 2, n. 41, set. 2021.

do) DOI: http:/dx.doi.org/10.5965/1414573102412021e0210

Este artigo passou pelo Plagiarism Detection Software | iThenticate 
As reverberações de Pega Teatro, de Joana Lopes: Contribuições para uma pesquisa em teatro educação

Theda Cabrera

Francisco Souza da Silva²

\title{
Resumo
}

Este artigo trata de parte da trajetória da arte educadora brasileira Joana Lopes, especialmente das proposições práticas voltadas ao jogo dramático. Por meio de comentários a algumas de suas obras cênicas e de reflexões registradas sobre o seu fazer discutem-se alguns aspectos de sua proposta autoral de pesquisa em teatro educação. Mais do que revelar traços que possam ser identificados como datados e superados em um fazer artístico, interessa evidenciar o caráter precursor e investigativo de uma arte educadora que segue produzindo e refletindo sobre múltiplas abordagens ao jogo dramático.

Palavras-chave: Jogo dramático. Teatro educação. Arte educação.

The reverberations of Pega Teatro, by Joana Lopes: Contributions to a research in theater education

\begin{abstract}
This article deals with part of the trajectory of the brazilian art educator Joana Lopes, especially the practical propositions focused on the dramatic play. Through comments to some of his scenic works and recorded reflections on his work, some aspects of his authorial proposal of research in theather-education are discussed. More than revealing traces that can be identified as dated and surpassed in an artistic work, it is interesting to highlight the precursor and investigative character of an art-educator that continues producing and reflecting on multiple approaches to the dramatic play.
\end{abstract}

Keywords: Dramatic play. Theater education. Art education.

Las reverberaciones de Pega Teatro, de Joana Lopes: Aportes a una investigación en teatro educación

\section{Resumen}

Este artículo trata de parte de la trayectoria del arte educadora brasileña Joana Lopes, especialmente de las propuestas prácticas dirigidas al juego dramático. A través de comentarios a algunas de sus obras escénicas y de reflexiones registradas sobre su obra, se discuten algunos aspectos de su propuesta autoral de investigación en teatro educación. Más que revelar rasgos que puedan ser identificados como anticuados y superados en un hacer artístico, interesa evidenciar el carácter precursor e investigativo de una arte educadora que sigue produciendo y reflexionando sobre múltiples aproximaciones al juego dramático.

Palabras clave: Juego dramático. Teatro educación. Arte educación.

${ }^{1}$ Pós-Doutorado e Doutorado em Educação pela Universidade de São Paulo (USP). Mestre em Artes e Bacharel em Artes Cênicas pela Universidade Estadual de Campinas (Unicamp). Professora no Ensino Superior em cursos de Licenciatura em Arte-Educação e em Teatro. thedacabrera@yahoo.com.br

\section{(9) http://lattes.cnpq.br/8714571010712198 (iD) http://orcid.org/0000-0002-8066-8574}

${ }^{2}$ Mestre em Artes PROFARTES /Instituto de Artes da Universidade Estadual Paulista (UNESP). Licenciado em Teatro pela Universidade de Brasília (UnB). Bacharel e Licenciado em Ciências Sociais pela UNESP. Professor de Arte na Rede Municipal de Cubatão.francisco_sociais@yahoo.com.br

(9) http://lattes.cnpq.br/5773182875872525 iD https://orcid.org/0000-0001-6839-063X 
Joana D’Arc Bizzotto Lopes nasceu em 14 de março de 1938, na cidade de Belo Horizonte, MG. Filha de um guarani que migrou para a sociedade das elites brancas e se tornou militar e de uma mulher de origem nobre austríaca. Joana viveu sua infância em Minas Gerais, e por volta dos anos 1950, muda com a família para São Paulo, onde estuda no Colégio Mackenzie e frequenta a Escola de Bailado do Teatro Municipal de São Paulo. No Rio de Janeiro, a partir de 1966, frequenta a Escola de Arte do Brasil e a Escola Nacional de Teatro. No início da década de 1960 Joana atua como professora alfabetizadora de inspiração freiriana. Em 1971, no Paraná, realiza oficinas de teatro na Faculdade de Filosofia da Universidade Estadual de Londrina, o que a leva a fundar o Teatro Escola Pindorama, que atendia à população marginalizada de lavadeiras e boias frias de um conjunto habitacional em Londrina. Esta e muitas experiências de inspiração freiriana voltadas ao ensino de teatro propostas por Joana acontecem entre as décadas de 1970 e 1980, em diversas regiões do Brasil que, durante a Ditadura Militar (1964-1985) atua primeiramente na legalidade e em seguida na clandestinidade como arteeducadora ${ }^{3}$ e jornalista ${ }^{4}$. Joana Lopes foi uma das criadoras do jornal feminista Brasil Mulher, em 1975, contribuindo para a constituição da imprensa alternativa feminista e a luta das mulheres pelas causas feministas e contra a Ditadura Militar. Em 1979, ela foi obrigada a deixar o jornal, a universidade e os projetos de teatroeducação para recomeçar a vida mais uma vez na capital paulistana.

De volta à São Paulo, Joana foi professora de Expressão Dramática na Dança no Balé da Cidade de São Paulo, na gestão de Klauss Vianna. Neste período do início da década de 1980 Joana cria duas obras importantes naquele momento de reabertura política: Vesperal Paulistânia ${ }^{5}$ e Tribunal Tiradentes ${ }^{6}$, ambas em 1983.

Na década de 1980 Joana participa da fundação do Departamento de Artes Corporais no Instituto de Artes da Universidade Estadual de Campinas (UNICAMP),

3 Para saber mais a respeito das censuras e perseguições sofridas por Joana, acesse: <https://medium.com/@fermentofeminista/joana-lopes-afronta-\%C3\%A0-ditadura-militar-epersegui\%C3\%A7\%C3\%A3o-db585ea6a617>. Acesso em: 20 fev. 2020.

${ }^{4}$ Sobre a atuação como jornalista veja mais em: Debértolis, 2002; Leite, 2003. Cardoso, 2004.

${ }^{5}$ Para saber mais, veja em: https://www.joanabizzottolopes.com/vesperal-paulistnia. Acesso em: 27 jan. 2021.

${ }^{6}$ Para saber mais, veja em: https://www.joanabizzottolopes.com/tribunal-tiradentes. Acesso em: 27 jan. 2021. 
onde atua como docente e pesquisadora entre 1987 e 2007 . Entre 1992 e 2000 atua também como professora visitante da Universidade de Bolonha, Itália, a convite da professora e pesquisadora de História da Dança Eugenia Casini Ropa, sua grande amiga e interlocutora. Durante e década de 1990 Joana ministra também aulas na Civica Scuola di Animazione Pedagógica di Milano, Itália e estabelece forte colaboração com a artista educadora italiana Loredana Perissinoto $^{8}$ e artistas e pesquisadores na França, como o casal de mestres de dança Françoise e Dominique Dupuy ${ }^{9}$. Desde meados da década de 1980, quando entra em contato com Maria Duschenes, Joana vai se tornando especialista em arte do movimento expressivo (Sistema Laban) e nas décadas seguintes seu trabalho enquanto pesquisadora e artista se dirige cada vez mais à área da dança, dança teatro e ensino-aprendizagem da expressão dramática na dança a partir do jogo dramático, o que culmina na elaboração da Coreodramaturgia e, mais recentemente, da Coreotopologia. Esta faceta de Joana mais ligada à dança e dança teatro não será enfocada no presente artigo.

São inúmeras suas coreodramaturgias, entre elas A Flor Boiando Além da Escuridão, criada e apresentada a convite da Universidade de Bolonha; o espetáculo Pra Weidt, O Velho, produzido pelo SESC com estreia na Bienal SESC de Dança em 2007, cumprindo temporada em São Paulo em

\footnotetext{
A colaboração entre Joana Lopes e Eugenia Casini Ropa se deve a convites de Eugenia Casini Ropa a Joana Lopes para colaborações entre 1992 e 2000, enquanto professora visitante no DAMS- Dipartamento di Musica e Spetacolo da Universidade de Bologna, Itália e na curadoria de Eugenia Casini Ropa para apresentações na Itália de espetáculos dirigidos por Joana Lopes em 1999 (veja em: <https://archivi.dar.unibo.it/files/muspe/wwcat/soffitta/1999/danza/appunta.html> e < https://www.joanabizzottolopes.com/jogos-arcaicos-entre-d-e-o>, Acessos em: 26 jan. /2021) e em 20062007 (veja mais em: <https://www.joanabizzottolopes.com/a-flor-boiando-alm-da-escurido> ; < https://archivi.dar.unibo.it/files/muspe/wwcat/soffitta/2007/danza/buoncompleanno.html> e e < https://www.teatro.it/notizie/teatro/bologna-rende-omaggio-alla-danza-di-kazuo-ohno>. Acessos em: 26 jan. 2021). Houve também a reciprocidade, com convites de Joana Lopes (Unicamp) à Eugenia Casini Ropa para colaborações no Brasil em 1996 e 2002, como, por exemplo em 1994 no 3‥ Encontro de Dança Arte do Movimento promovido pelo Sesc, programa disponível no acervo do Museu da Dança, disponível em: http://acervomuseudadanca.com.br/3o-encontro-de-danca-arte-do-movimento-laban-1994/. Acesso em: 26 jan. 2021. Em 2020 Eugenia Casini Ropa prefacia o livro de Joana Lopes A dança elementar, lançado no Brasil em 2020 pela Stacchini Editorial.

${ }^{8}$ Loredana Perissinotto, pesquisadora e animadora teatral muito ligada ao movimento teatri per ragazzi (teatro para crianças e jovens) na Itália, esteve na Unicamp em 1997, a convite de Joana Lopes e ministrou um curso com duração de um semestre.

${ }^{9}$ Para saber mais sobre a colaboração entre Joana Lopes e Loredana Perissinotto, Eugenia Cassini Ropa e o casal Dupuy, veja Jornal da Unicamp, ano IX, no. 102, agosto de 1995, p.12, disponível em: https://www.unicamp.br/unicamp_hoje/jornalPDF/JU_0102.pdf. Acesso em: 26 jan. 2021. "Joana Lopes também esteve bastante presente nos debates internacionais promovidos pelo Institut de Pédagogie Musicale et Chorégraphique de Paris (IPMC) assim como contribuiu com a revista Marsyas, editada por Dominique Dupuy, através do artigo La tradition ou la maîtresse invisible (Lopes, 1994), posteriormente traduzido para o português e publicado na revista Repertório (Lopes, 2016)" (Madureira; Yonashiro, 2020, p.3).
} 
2014 (Lopes, 2017b, s/p). ${ }^{10}$

Em seu livro mais conhecido, Pega Teatro11 (1981, 1989, 2017a) Joana Lopes apresenta uma prática e reflexão sobre o teatro educação. Por meio das narrações de experiências dos trabalhos que realizou entre os anos 1970 com operários no ABC paulista, com comunidade na periferia de Londrina e com outros grupos em São Paulo, apresenta uma metodologia de trabalho artístico-pedagógico em artes cênicas.

O processo de elaboração das práticas cênicas ocorridas durante a década de 1970 no auge da Ditadura Militar brasileira, cujos relatos e registros originais alguns foram confiscados e outros perdidos, resultam num esforço de reconstituição de memórias reunidas por Joana ao publicar a primeira edição de Pega Teatro em 1981, quando no Brasil eram ainda muito poucas as referências sobre teatro-educação, bastante mescladas até aquele momento com o teatro para a infância: Maria Clara Machado, Tatiana Belinky, Peter Slade, Olga Reverbel. Foram contemporâneos e interlocutores de Joana Lopes durante a década de 1970 Augusto Boal e Paulo Freire e pode-se constatar pelos relatos em Pega Teatro a influência destes dois últimos.

Neste artigo interessa revelar um pouco mais do trabalho de Joana numa leitura diversa e complementar à outras que se focaram basicamente nas análises a partir de leituras de Pega Teatro nas edições publicadas em 1981 e 1989 e não se detiveram a apresentar ou analisar outras práticas e reflexões presentes no trabalho de Joana da década de 1990 em diante, porém ainda relacionadas ao arcabouço presente em Pega Teatro. A terceira edição de Pega Teatro (2017a), foi revista e ampliada, pretendendo retomar e rediscutir conceitos de um ponto de vista diverso e/ou complementar à de outros autores quando se referenciaram às duas primeiras edições e apresentar brevemente algumas das reflexões mais atuais de Joana, de modo que Pega Teatro seja (re)lido na atualidade, evitando ser fixado como algo datado e inteiramente superado, que 'saiu de moda'. Este artigo

${ }^{10}$ Informações biográficas disponíveis no site oficial de Joana Lopes:

https://www.joanabizzottolopes.com/currculo. Acesso em: 22 fev. 2020.

${ }^{11}$ Publicado pela primeira vez em 1981, a 2a . edição publicada em 1989 (ambas esgotadas) e 3a edição revisada e ampliada publicada em 2017. 
se propõe a ser uma espécie de reconhecimento do legado de Joana Lopes a alguns pesquisadores, possibilitando diálogo com pesquisas atuais.

Dessa forma, este artigo trata de um estudo de parte de sua trajetória como artista-educadora interessada no jogo dramático espontâneo com crianças e adultos e não pode ser considerado uma pesquisa biográfica, nem da totalidade de sua obra. O artigo enfoca apenas alguns acontecimentos e as experiências que são narradas pela autora em Pega Teatro (2017a), de modo a buscar demonstrar o desenvolvimento de uma proposta singular de ensino de teatro que em alguns momentos se contrapõe, em outros complementa, porém em todos os momentos dialoga com o seu tempo, dentro de um campo teórico do surgimento de uma concepção de arte educação no Brasil desde a década de 1960, essa tendo como principais referenciais Herbert Head, Augusto Rodrigues, Paulo Freire. Joana Lopes possui um modo peculiar de processar diferentes referências brasileiras e estrangeiras como Huizinga e Caillois; Rudolf Laban e Maria Duschenes; Gisèle Barret, entre outros. Estas concepções de arte educação se desenvolvem recebendo contribuições de Lopes e de seus/suas contemporâneos como Luísa Barreto Leite, Augusto Boal, Ana Mae Barbosa, Ingrid Koudela, Rosa lavelberg, Acácio Valim Jr., Karin Muller, Ulisses Cruz, Sueli Vital, Maria Momensohn, Lenira Rengel, o diretor brasileiro radicado em Portugal José Caldas ${ }^{12}$, entre outros. Desde o início de sua atuação no corpo docente da Unicamp Joana Lopes teve como estudantes de graduação e pós-graduação artistas e pesquisadores como Ivan Vilela, Milton Andrade, Demian Reis, Rafael Madureira, Maria Cristina Pinto, Juliana Moraes, Theda Cabrera, Andreia Yonashiro, Renata Fernandes, Melina Schialom, entre outros.

Ao longo de sua jornada poética, [Joana] atuou ao lado de figuras emblemáticas da política, da arte e da educação, tais como Fayga Ostrower, Paulo Freire, Herbert de Souza, Jorge Mautner, José Roberto Aguilar, Lygia Clark, Hélio Oiticica, Caetano Veloso, Luís Otávio Burnier, Katherine Dunham, Marilia de Andrade, Maria Clara Machado, Ana Mae Barbosa, Carlos Drummond de Andrade, Gerda Alexander, Eugenia Casini Ropa, Françoise e Dominique Dupuy, Maria Duschenes e, com especial afeição, Klauss Vianna (Madureira; Yonashiro, 2020, p.2). 
As práticas elaboradas por Lopes durante a década de 1970, relatadas desde a primeira edição de Pegá Teatro em 1981 se baseavam no que ela nomeava como jogo dramático espontâneo, que ela definia da seguinte maneira:

Na dramatização espontânea, o atuante não é um mediador da expressão criada por um dramaturgo, interpretada por um diretor de cena, juntamente com seu grupo de atores. No jogo dramático espontâneo, o atuante é fonte de expressão, fazendo o jogo do autor-ator, portanto a metamorfose, fenômeno básico desse jogo, aparecerá como resposta genuína do atuante interessado em transformar-se num outro, o que significa ampliar seu universo de comunicação, sua capacidade de expressão e sua criatividade (Lopes, 2017a, p.96).

Sobre o momento da criação do conceito de jogo dramático espontâneo Joana afirma que:

não havia a necessidade de delimitação da abordagem teórico-prática para o ensino do teatro do conceito a partir deste conceito autonomeado jogo dramático espontâneo, não havia no Brasil tantas outras definições às quais se aproximar e das quais se diferir de outras noções de jogo dramático (informação verbal, 2020) ${ }^{13}$.

Joana Lopes cunha o termo jogo dramático espontâneo, bastante interessada na observação de atuantes de diferentes idades e condições para transbordar à questão da técnica teatral. A singularidade do conceito de jogo dramático espontâneo forjado por Lopes na década de 1970 se situa num contexto maior de sua trajetória, o que ela autonomeia de Teatro Antropomágico, que ela assim define:

Nesse sentido a primeira questão abordada no nosso fazer artístico ocorre no nível de recuperar o sentido do jogo, característica fundante de nossa criação autodenominada Antropomágica. Por outro lado, e, inevitavelmente, ocorre a necessidade de buscar uma interdisciplinaridade das linguagens artísticas como também construir uma informação que não se restringisse à cena teatral mas pertencesse à história, à antropologia cultural, à educação como campos prioritários de apoio. [...] Reforço com este trabalho a crença na ARTE VIVA, fundamento que descreverei como TEATRO ANTROPOMÁGICO, de modo algum discurso restaurador da magia teatral.

Apresento formas de agir, pensar e adestrar-se com o objetivo de também desconstruir mitos que rezam a 'livre expressão'; improvisação

13 Informação verbal coletada em encontro entre pessoas autoras deste artigo e Joana Lopes, na residência desta em São Paulo, SP em 25 de janeiro de 2020. 
do ator, algo intocável por propostas que possam vir do exterior e que pretendam desconstruir a expressão, ou melhor a LIVRE EXPRESSÂO CONDICIONADA POR ESTEREÓTIPOS (Lopes, 2008, s/p).

Se hoje nos indagarmos sobre os pontos de encontro e de fricção dessa abordagem do jogo dramático espontâneo com outras abordagens de jogo dramático podemos citar como outros estudos que mencionam o trabalho de Lopes e a classificam (Pupo, 2005, André, 2007). Porém a própria Lopes, ao ser inquirida sobre isto em 2020 (informação verbal) ${ }^{14}$, mesmo sabendo das definições extrínsecas, concomitantes ou posteriores à criação de suas práticas e que buscam algum tipo de classificação que a agrupe próxima à outras referências de jogo dramático "não se interessa a fazer comparações ou dar maiores definições do que aquelas publicadas". Como autores deste artigo, cremos que por ser uma precursora, Lopes não se interessa em comparar seu trabalho pioneiro à de outros pioneiros e tampouco de se vangloriar das influências que exerceu e ainda exerce em tantos trabalhos derivados ou em comentaristas de seu trabalho que pretendem classificar, datar e aprisionar em conceitos estanques uma prática à qual não tiveram acesso direto. Como Joana, preferimos seguir nesta reflexão adotando uma perspectiva fenomenológica, de busca de compreensão e contextualização dos fenômenos tais como se apresentaram no momento histórico em que foram criados sem, no entanto, incorrer no furor pedagógico (termo cunhado por Jung) de classificar, catalogar, comparar o que tem em si e per si seu valor, que deixa um legado que pode vir a influenciar gerações sucessoras em suas práticas e reflexões sem, no entanto, exigir filiação exclusiva ou excludente.

Parafraseando a própria Lopes: longe de buscar um "modelo para tecer o curso da verdade" (Lopes, 1989, p.64), "não aceitamos partir de modelos esquemáticos montados através de técnicas predeterminadas" (Lopes, 1989, p. 65).

Não aceitamos um processo de arte-educação que se apoie na generalização traduzida por técnicas padronizadas que, por sua vez, causam uma visão simplista e simplificante do que possa ser a união de

${ }^{14}$ Informação verbal coletada em encontro entre pessoas autoras deste artigo e Joana Lopes, na residência desta em São Paulo, SP em 25 de janeiro de 2020. 
arte e educação num só movimento crítico (Lopes, 1989, p. 63).

Ainda sobre uma definição sobre o campo do jogo dramático e onde o trabalho de Joana se insere ou se relaciona com outras tendências, adotamos aqui um referencial proveniente de referências que Joana passa a utilizar e citar na década de 1990, sempre em relação com o jogo dramático espontâneo e que está presente num dos artigos de Pega Teatro (2017a):

Adoto aqui a definição de Huizinga para jogo: é uma situação temporária, regrada, convencional, ‘que cria ordem e é ordem' (Huizinga, 1999, p. 13). E me refiro a um tipo específico de jogo, o jogo de categoria mimicry. um jogo que pede a aceitação temporária de uma ilusão na encarnação de um comportamento, portanto dando ao jogo caráter de mímica, disfarce, simulação, simulacro (Caillois, 1990).

Caillois reconhece o jogo como fenômeno antropológico e vê o jogo de simulação em inúmeros contextos, desde os mais simples aos mais complexos: desde as imitações infantis; brincadeiras com bonecas; máscaras e disfarces até o teatro e as artes do espetáculo em geral. Se aceitarmos como premissa esta observação de Caillois, podemos verificar diferentes gradações de jogo de categoria mimicry (Caillois, 1990) no contexto do teatro-educação presentes desde as brincadeiras dramatizadas mais simples das crianças pequenas (brincadeiras dramatizadas de faz-de-conta) até as apresentações mais organizadas em torno do espetáculo teatral na escola. Tentando 'desembaraçar os fios' (Pupo, 2005) do que se praticou e se pratica em termos de arteeducação no Brasil desde meados da década de 1960 até hoje no Brasil (Mate, 2010) podemos chegar a inferir que as manifestações dramáticas de amadores e diletantes do jogo mimicry possuem gradações que englobam desde o jogo dramático espontâneo (Lopes, 1989), jogo dramático infantil (Leenhardt, 1977; Slade, 1978), teatro do oprimido (Boal, 1983, 1996, 2005) até o jogo teatral (Spolin, 1979, 1999, 2001). Longe de hierarquizar ou pretender dar um juízo de valor, cada uma destas gradações tem seu valor intrínseco e interessa aqui conhecer melhor algumas destas gradações, levando em conta o fazer artísticopedagógico de artistas-educadores, professores de teatro, professores de educação infantil e ensino básico, formadores de licenciandos em Artes Cênicas e em Pedagogia, educadores sociais, pais e mães, entre outros (Cabrera In: Lopes, 2017a, pp 211-212).

De nosso ponto de vista, Pega Teatro (2017a) não se apresenta nem é um manual com atividades prontas, mas uma etnografia das práticas de ensino de teatro, que inspiram e oferecem parâmetros para refletir sobre como propor o teatro como processo educativo em uma perspectiva emancipatória. Afirmamos que seus escritos são como uma etnografia por perceber as características deste 
tipo de pesquisa e escrita. Como aponta a antropóloga Dra. Leila Jeolás, do Departamento de Ciências Sociais da UEL, no prefácio a 3a edição do livro, aproximando o trabalho de Teatro-Educação de Joana ao ofício do antropólogo:

O primeiro paralelo que se pode fazer refere-se a dois princípios fundamentais ao método etnográfico constitutivo da prática antropológica: os comportamentos humanos só podem ser apreendidos se levados em conta os contextos sociais nos quais atuam e, para compreendê-los, há necessidade de se apreender o "ponto de vista do Outro". Estes princípios percorrem a história e a prática desta área do conhecimento, cujo principal desafio é a compreensão do Outro em um exercício permanente de não se deixar guiar por categorias dadas a priori, moderno-ocidentais, etnocêntricas e colonialistas, naquilo que é seu caráter constitutivo: Olhar, Ouvir, Escrever (Jeolás In: Lopes, 2017a, p.16).

Olhar, ouvir, escrever - três ações que expressam a dinâmica da pesquisa etnográfica. Olhar uma realidade diferente daquela em que vive o pesquisador, munido de pressupostos que permitem olhar e perceber o outro e seus contextos.

Ouvir é estar atento aos significados expostos de maneira explícita, bem como aqueles que são compartilhados no confronto de dois mundos diferentes, ou seja, aqueles significados que são expressos quando se estabelece uma determinada relação de confiança.

Estabelecendo uma relação dialógica em que olhar e ouvir ocorrem em sinergia e retroalimentação, o confronto destes mundos se transforma em um espaço de partilha. Onde ocorre uma “fusão de horizontes", neste movimento mútuo de ouvir e ser ouvido (Oliveira, 2000).

Substituímos aqui o termo escrever - a etapa da narração e da reflexão da pesquisa etnográfica- por engajar. Nas narrativas descritas por Joana é possível perceber que suas oficinas e encontros se transformavam neste momento de "fusão de horizontes". Em que ela vivenciava com os aprendizes-atuantes as descobertas e os anseios no exercício de compreender a realidade, e pensar formas de atuar nela.

Neste sentido, mais do que olhar e ouvir o outro, Joana engajou-se nos outros. Joana afirma que seu sistema de trabalho e de pesquisa são fundamentados na alteridade. Assim como em antropologia a alteridade é 
elemento essencial na investigação, nos processos de aprendizagem desenvolvidos pela autora é o que torna possível o contexto para a criação e experiência coletivas.

Assim como o antropólogo, no campo de pesquisa, 'se desnuda' de seus conceitos e pré-noções sobre o outro, o arte-educador também se desnuda dos cânones estetizantes, escolarizantes e pedagogizantes para valorizar as realizações dos aprendizes, e assim conseguir olhar e ouvir, ao mesmo tempo em que é observado e ouvido na mesma intensidade. A alteridade que permite a fusão de horizontes e a construção de um horizonte compartilhado, revelador de realidades e potencializador de ações e atitudes.

Em conversa com Lopes em janeiro de 2020, ela rememora a ação cênica Vila da Prosperidade, conduzida por ela e realizada em uma escola estadual no bairro Prosperidade, no período em que Joana desenvolveu um trabalho na Fundação das Artes de São Caetano do Sul (1980) no qual atores e atrizes da Fundação se relacionam com crianças e professores da escola estadual. Parecenos que, em seu modo muito singular de conduzir o jogo dramático ao olhar e ouvir os contextos e as necessidades de expressão dos atuantes ou jogadores, nos encontros em que fazer teatro eram a tônica, a ação cênica chegou a revelar a vida e os desafios daquela comunidade, na percepção atual de Joana. Nessa leitura, a alteridade não seria uma postura que surge mecanicamente, porém desenvolvida pela sensibilidade, pela abertura sincera ao outro e seus universos.

Cremos que foi essa ético-poética que vem possibilitando que os envolvidos em suas propostas nas últimas cinco décadas desenvolvam uma forma de expressar e comunicar muito singulares, percebendo a si mesmos e aos outros. Com sua forma de condução Joana busca superar determinações e estereótipos, não se limitar às metodologias tradicionais e padrões estéticos, sua proposta potencializa as capacidades dos atuantes tal como o jogo se apresenta no momento presente em um processo libertador de projeções em que haveria um ‘ideal’ a ser seguido ou perseguido.

Estar atento ao que os atuantes apresentam em suas falas, gestos, dramatizações, nos silêncios foi um dos elementos que veio permitindo a Joana 
empreender mais do que processos educativos, um processo emancipatório de construção de saberes e atitudes críticas.

Conhecer parte da trajetória de Joana é revelar parte da História do ensino de teatro no Brasil, especialmente pela proposta que perpassa o diálogo com as expressões populares, em que considera performática as ações dos vendedores de rua, como também podemos lembrar daqueles que cotidianamente se arriscam nos transportes coletivos das grandes cidades, seja vendendo produtos, apresentando trabalhos artísticos como poesia, slam, música, dramatizações e rimas para conseguirem recursos para suas existências ou planos particulares.

Repensar o 'teatro popular' não significa apenas questionar seus aspectos organizacionais, mas perguntar como ele poderá materializar a necessidade e a oportunidade de expressão das camadas populares. A nossa proposta inicial está na ideia de pensarmos um teatro popular como prática artística popular, ou seja, o povo fazendo teatro, como meio de recreação e educação (Lopes, 2017a, p.68).

São estas percepções e apontamentos que expressam visões de mundo de Lopes em relação aos contextos de desigualdade e diversidade presentes na realidade brasileira. Ao mesmo tempo, demonstram a potencialidade das formas de comunicação e expressão de cada atuante, seja ou não ele/a ator/atriz de profissão.

O desenvolvimento da materialidade do corpo está presente nessas manifestações do dia a dia, uma busca por uma maneira de comunicar de forma vital, pois estas pessoas rompem com seus modos de comportamento para concretizar suas necessidades e da observação desta 'performatividade' Joana extrai a percepção de que o jogo dramático espontâneo (Lopes, 2017a), sua presença em manifestações cotidianas pode ser uma base para a elaboração consciente do artista cênico no seu processo criativo em contexto extracotidiano.

As quadras de escolas de samba são outro exemplo dessa construção da materialidade do corpo. Joana investiga na década de 1990 essa monumental manifestação cênica inicialmente de cunho popular, e percebe que existe um caminho potente para a arte-educação, para um crescimento do atuante em busca de maturação de sua capacidade de elaboração expressiva e comunicante. 
Em depoimento para o projeto Percursos da arte na educação ${ }^{15}$, Joana Lopes afirma que não é que os processos de apreender os passos do samba sejam inerentes a aprendizagem em arte, mas aponta alternativas para pensar como esses processos de aprender e ensinar ocorrem.

Você vê uma criança de 4 ou 5 anos que aprende o passo do samba com a mãe, com a avó, com a outra que vai na quadra... o que que é aquilo?... É uma busca da materialidade de uma maneira impressionante. O corpo educado de uma maneira que é capaz de trabalhar o que a gente chama de breaks, né? Que é uma coisa complicadíssima, que é a mudança da direção espacial que muda toda a organização muscular e que ela trabalha com elegância e leveza, e que alguém lhe ensinou aquilo, não é espontâneo, não (Percursos, 2014, s/p).

A experiência da sambista na escola de Samba é um momento extra cotidiano, em que a pessoa se torna um outro, cultiva sua capacidade de metamorfose (Lopes, 2017a), de descentramento de seu 'eu cotidiano' e a possibilidade de adotar outras personas, diversas daquelas habituais.

Naqueles instantes em que na cadência do samba se desenvolve uma materialidade do corpo que difere do caminhar, do olhar do dia a dia, a pessoa que dança adquire o estatuto de um 'outro', assume outra persona, diversa da sua habitual e cotidiana. Assim, a menina que brinca pelas ruas de ser passista, joga como se fosse passista, vivência ser uma das passistas da escola, é aplaudida, reverenciada por uma plateia imaginária ao carregar consigo o símbolo da comunidade.

Esse interesse de Joana com os vendedores, artistas de rua e 'brincantes' das escolas de samba é coerente com sua busca como diretora-pedagoga e arteeducadora, principalmente em uma perspectiva dialética do teatro, como forma de expressar criticamente a realidade e comunicar a outros a sensibilidade poética e estética de um processo do fazer teatral na educação. Em suas propostas, Joana aposta que o grau de desenvolvimento da linguagem cênica se desenvolve junto com as necessidades de comunicar, é pelo desejo de comunicar-se que os

${ }^{15}$ Publicado em 2014, este projeto foi criado com o objetivo de preservar a memória da arte-educação no Brasil. Reúne 20 depoimentos de arte-educadores e pesquisadores com intenção de contribuir com o fortalecimento de uma cultura de valorização e preservação da memória da arte-educação no Brasil. Disponível em: https://www.youtube.com/watch?v=-0Xh901LZ48. Acesso em: 22 fev. 2020. 
atuantes buscam e elaboram as ferramentas necessárias para que aconteça uma comunicação efetiva com o outro.

Faz-se muito importante destacar a contribuição de Joana Lopes ao trabalho artístico-pedagógico quando ela adapta das ciências do conceito de metamorfose, como aquele processo em que os atuantes vão atingindo a maturação de sua capacidade de colocar-se no lugar de um 'outro', e de agir como este 'outro' faria em determinada situação, alcançando paulatinamente a capacidade de abstração e de alteridade.

Lopes afirma que a capacidade de metamorfose do jogador - ou como ela prefere nomear, atuante - é o fenômeno básico do jogo dramático espontâneo e a metamorfose

[...] aparecerá como resposta genuína do jogador interessado em transformar-se num outro, o que significa ampliar seu universo de comunicação, capacidade de expressão e criatividade. A metamorfose é o momento em que o indivíduo ultrapassa a si mesmo para elaborar a circunstância e a personalidade de um outro que independe da determinação de sua vontade ideal, interesse e características pessoais, físicas, éticas, morais, econômicas e políticas. [...]. Através do jogo dramático espontâneo o jogador liga a dimensão estética da vida a todas as outras que definem seu papel e função social.

No exercício dramático, a metamorfose como fenômeno básico requer um crescimento da capacidade de abstração, conceituação e descentralização individual, ou seja, um crescimento em direção à comunicação. Diríamos que quanto mais o indivíduo se distancia das evoluções em torno de seu umbigo, mais aumenta seu raio de ação e de sua interferência. Será a metamorfose o sinal deflagrador de cada fase que percebemos no jogo dramático espontâneo, pois é a partir da capacidade de imitar e também da necessidade de fazê-lo que o nosso jogador transmitirá sua relação com o mundo mais próximo e mais longínquo (Lopes, 1989, p.61-62).

Ao agir como se eu estivesse na situação de um 'outro': 'se eu fosse esta outra pessoa, na situação apresentada, o que eu faria?', pouco a pouco o jogador poderia chegar a consentir dentro de si este giro antropológico que exercita a alteridade. O jogador vai cultivando a capacidade de agir em situações ficcionais que talvez não the sejam conhecidas ou cotidianas, assumindo atitudes que talvez não the sejam habituais. Deste modo o jogador exercita sua potencialidade de 'colocar-se no lugar do outro', tratando de compreender pela ação, os desejos e necessidades que movem as pessoas e grupos sociais. 
O desenvolvimento da capacidade de metamorfose é um amadurecimento do Ser, não é somente a aprendizagem de máscaras sociais de bom comportamento, cordialidade, formalidade. Adquirir idade não significa necessariamente, adquirir maturidade. Quanto a isto, Lopes afirma claramente: "As etapas evolutivas do jogo dramático não podem ser delimitadas com rigidez, a partir de uma referência cronológica nem podem ser consideradas resultados máximos de um indivíduo" (Lopes, 1989, p.68). Lopes delineia alguns contornos de estágios de maturação da capacidade de metamorfose, que vão desde as mais simples das brincadeiras dramatizadas (primeiras imitações; fundo de quintal; fazde-conta), "não sendo um ato consciente do uso e do meio dramático como linguagem" (Lopes, 1989, p.71) e caracterizadas pela [...] exteriorização afetiva através de pequenos jogos que simbolizavam a experiência de cada um [...], [onde a] dramatização era um estado de vida interligado com o cotidiano" (Lopes, 1989, p 96).

Se o jogador segue experienciando a expressão dramática e se desenvolvendo nela, pode atingir um grau mais complexo de brincadeira dramatizada (que Lopes nomeia de intenção de realismo e realismo) em que ocorre uma "defasagem entre o que o atuante quer expressar e o que ele consegue" (Lopes, 1989, p.84). É isto que o levará o jogador a buscar aperfeiçoar-se na linguagem. Nestas fases o jogador busca "soluções cênicas a partir da experiência cotidiana" (Lopes, 1989, p.85).

Se o jogador segue ainda mais cultivando sua expressão dramática, atinge um grau máximo de complexidade que atinge o jogo dramático (já não mais 'espontâneo', agora ato intencional, cuja meta é de comunicação) propriamente dito, como [...] experiência estética, pois é intencionalmente criada pelo participante como a finalidade de comunicar-se, dar vazão às suas ideias, divertirse e criar personagens independentes de seu próprio caráter (Lopes, 1989, p.97).

No que Lopes nomeia de jogo dramático, onde a "referência [é] a vida social, e não mais exclusivamente a experiência de vida do participante face à vida social” (Lopes, 1989, p. 96) as "regras próprias [...] são manipuladas pelos atuantes-atores numa experiência grupal” (Lopes, 1989, p. 96). 
Parece-nos que aí, neste ponto onde se atinge um grau de maturação da capacidade de metamorfose do jogador mais realística (em esclarecimento à qualquer desconfiança que possa associar o que Lopes chama de intenção de realismo e realismo com uma estética realista-naturalista), o jogo dramático observado por Lopes se aproxima da acepção francesa de jogo dramático- jeu dramatique (Pupo, 2005) que o leitor brasileiro teve a oportunidade de tomar contato em língua portuguesa principalmente por meio de Ryngaert (1981; 2009). É quando o jogador passa a ter a percepção da "exigência do espectador como motivação" (Lopes, 1989, p.96), entendendo o teatro como "opção de linguagem artística” e que o jogo poderá ser "ilusionista ou anti-ilusionista, baseando-se nesses dois modelos clássicos que não são suficientes para enquadrar todas as manifestações que possam ser criadas” (Lopes, 1989, p.97). Eu incluiria aí nestas outras "manifestações que possam ser criadas" outras formas de expressão dramática: inspiradas no arcaísmo fértil das protodramáticas (danças dramáticas populares do Brasil coletadas por Mário de Andrade e colaboradores nas viagens das Missões Folclóricas de 1934) ou pós-dramáticas (como a arte da performance).

Parece-nos que reconhecer diferentes e diversas gradações da capacidade de metamorfose do atuante é um grande mérito no trabalho investigativo de Joana. Em nossas experiências enquanto artistas, educadores e pesquisadores, ao observarmos jogos dramáticos espontâneos em crianças e ao conduzirmos práticas de jogo de categoria mimicry (Caillois, 1990) com diferentes faixas etárias (pessoas entre 5 e 83 anos) em contextos de educação não-formal e formal, constatamos o quão valioso é esta visada proposta por Joana à respeito das diferentes gradações possíveis, o quanto são diversas as capacidades de metamorfose de diferentes atuantes e em diferentes momentos de um mesmo atuante. Também contribui muito em nossas práticas, ao reconhecer estas gradações, fomentar por meio de diferentes e diversos recursos, uma paulatina aquisição da linguagem dramática e cênica, o quanto reconhecer qual a capacidade de um atuante ou grupo naquele momento é ponto de partida para intervenções artístico-pedagógicas mais precisas. Sem criar expectativas de como o jogo 'deveria ser' ou gostaríamos que fosse visto' de ponto de vista adultocêntrico, urbano, verbo-racional, branco-ocidental, escolarizante, que parte 
de um conceito espetacularizante, pois como já diz a canção "Narciso acha feio o que não é espelho".

Para nossa prática, o que Joana propunha desde 1973, quando realiza os primeiros esboços do capítulo Somos todos atuantes, alguns serão atores de profissão, que consta das três edições de Pega Teatro, continua sendo um convite à sensibilizar-se diante do potencial criativo de atuantes e, principalmente, nosso enquanto artistas, educadores e pesquisadores, de aprender a valorar uma 'gema bruta', de reunir as condições para que atuantes encontrem por si meios de expressar e de chegar a comunicar aquilo que necessitam e desejam, de modo que a relação de condutor e de atuante seja um 'fazer junto' porém não fazer pelo outro, ou como Joana sempre diz, parafraseando Lao Tsé: "não damos o peixe, te ensinamos a pescar". Em muitas ocasiões, Joana atua como mestre de jogo, dirigindo a cena enquanto ela acontece, criando exercícios, propondo recursos técnicos 'de momento' quando o atuante 'derrapa' ou 'estagna', sempre apostando naquilo que o movimento expressionista na arte, especialmente a precursora da expressão de expressão Mary Wigman afirmava de que: o artista (atuante, em nosso caso), num processo de escuta de si mesmo, pode conhecer suas forças criadoras e, ao mesmo tempo, conseguir os meios para exprimir estas forças com se manifesta expressivamente partir de uma necessidade interna. E, ao mesmo tempo, de forma não-excludente, complementar e complexa, cremos que as técnicas e estéticas não são um fim em si mesmas. "É por isso que não definiremos a aquisição de uma técnica como anterior à elaboração dum discurso. O fundo não pode ficar subordinado à forma ou visar apenas uma clarificação desta” (Ryngaert, 1981, p.45). Na busca da elaboração de um discurso é que recorre-se às técnicas necessárias, nos momentos que se mostram necessárias. É importante propor diferentes estímulos técnicos individualizados, pois cada pessoa elabora seu discurso de acordo com quem e as referências simbólicas, imagéticas, culturais que possui e também com um alargamento possível de horizontes. Soluções estetizantes precipitadas interrompem ou obstaculizam o processo de balbucio de uma fala nascente do jogador.

Em todos os experimentos narrados por Joana Lopes é possível perceber que a aprendizagem se consolida em um processo que não necessariamente tem 
uma progressão determinada de etapa, e isso não significa que seja uma ação desordenada, sem critérios; pelo contrário, quando se diz que não há um encadeamento previsível das etapas, isso revela que não é rígido nem autoritário, mas que o processo de maturação dos atuantes vai sendo desenvolvido conforme as demandas e ações que são vivenciadas individualmente e no coletivo. Se em Pega Teatro há alguma menção à uma interpretação mais simplista de Piaget quando Lopes se refere a fases ou etapas de desenvolvimento, esta menção é datada de um período em que Piaget era exaltado no Brasil, especialmente na década de 1980 no Colégio Vera Cruz, em São Paulo/SP, onde Joana Lopes lecionava Arte. Não temos registro de que Joana conhecesse a abordagem de Elkonin sobre jogo, mas supomos que se ela conhecesse teria sido mais afim com seus preceitos e procedimentos de trabalho, que dialogam melhor com uma abordagem vygotskiana do que piagetiana.

Cremos ser importante fazer uma ressalva a uma abordagem do jogo dramático exclusivamente piagetiana. Discordamos da rigidez de fundo 'evolucionista' que porventura estivesse implícito na concepção de Joana de fases evolutivas do jogo dramático: nem sempre os estágios das crianças mais velhas são mais 'evoluídos' do que os das crianças pequenas. Não acreditamos que os homens ditos 'primitivos' são menos 'evoluídos' do que aqueles que vivem na sociedade urbana ocidental contemporânea. Preferimos encarar esta questão dos diferentes estágios do jogo dramático como uma divisão heurística em que o mais importante é a questão da maturação, do abandono progressivo e voluntário de um egocentrismo, da aceitação da pessoa que é importante conviver no coletivo e para isto é importante olhar e escutar os outros, colocar-nos em seu lugar. Basta olhar ao redor e podemos constatar que muito pouco da capacidade de colocarse no lugar do outro tem sido exercida. Basta olhar com honestidade para muitos de nossos atos na vida cotidiana para verificarmos que ainda nos falta exercitar mais esta potencialidade. Então, ao invés de encararmos como especialistas uma questão puramente técnica da maturação da capacidade de simbolização da criança, é preciso 'colocar-se em jogo', aceitar a responsabilidade desta educação por meio do jogo dramático que nos diz respeito e começa com a aceitação da autoformação de nós mesmos. 
Percebemos que essa visada sobre a maturação da capacidade de metamorfose tem um potencial libertador e subversivo. Não significa, necessariamente, um engajamento político partidário; mas, acima de tudo, exercer uma responsabilidade ética que está potencial em cada pessoa. A uma maturação da capacidade poética e estética seria desejável uma correspondente maturação ética, e vice-versa. Suprimir ou fornecer parcos meios de desenvolvimento destas potencialidades é uma política educacional de longuíssimo prazo que tem sido muito bem sucedida na escola ocidental dita pública e dita democrática.

Concordamos com Joana quando acolhe a contradição como ponto importante e vital no processo de criação, pesquisa, de ensino-aprendizagem em que as condições, espaciais, temporais e humanas envolvidas neste processo precisam ser levadas em conta para a busca de recursos e ferramentas para lidar com as situações do presente no presente.

Em que estágio de maturação de nossa capacidade de metamorfose nos encontramos neste momento? Diante de diferentes pessoas e diversas circunstâncias nossa atitude é sempre a mesma? "A criatividade e a expressão não são capacidades naturais com níveis inalteráveis, obedecendo à mesma mobilidade e abrangência que a vida do indivíduo possui” (Lopes, 1989, p.59).

Sendo assim, o jogo dramático visto como ferramenta para alargar a experiência de vida, desenvolver a percepção, sensibilidade, inteligência, a capacidade criadora. Ou ainda, reviver essa capacidade não-desenvolvida ou suspensa ao longo da vida, já que o entendimento de Joana Lopes é de que essas capacidades se fragmentam após a infância (ou ainda nela), e o jogo dramático seria uma forma de crianças, jovens, adultos e idosos se reencontrarem com essas capacidades (Cabrera, 2016).

Sendo assim, Joana afirma que a pessoa atuante, ao vivenciar a alteridade, este processo a auxilia na compreensão de si e do seu espaço social. Quanto mais a pessoa atuante cultiva a capacidade de metamorfose, de alteridade, de empatia, tanto mais ela poderá ter liberdade de assumir papéis e, ao mesmo tempo, ter domínio linguístico da linguagem dramática, podendo exercer ou não a profissão de ator ou atriz a partir do momento em que atinge uma maturação interior e 
recebe orientações éticas, poéticas e estéticas de outros, que podem ser parceiros de jogo, professores, educadores, diretores de teatro, entre outros.

Sem idealizações, Joana Lopes busca uma espontaneidade que evite a "livre expressão condicionada por estereótipos" (Lopes, 1981, 1989, 2017a). Ela reconhece que:

A criatividade e a expressão não são capacidades naturais com níveis inalteráveis, obedecendo à mesma mobilidade e abrangência que a vida do indivíduo possui. À vitalidade da expressão e da criatividade correspondem fases de evolução, ou estruturas organizadas e caracterizadas, de forma que se torne possível a sua observação pelo jogo dramático [...] (Lopes, 1989, p.59).

Não está presente nas duas primeiras edições de Pega Teatro o mantra que Joana professa ao longo das décadas de 1990 e segue entoando, suas obsessões como artista e pesquisadora que só foram se decantando e refinando com o passar do tempo e as inúmeras experiências profissionais e pessoais das últimas décadas: "o que nos interessa é utilizar a expressão artística como instrumento de um processo de humanização do ser humano e nosso caminho para isso é indireto, relacional, por vias perceptivas e analógicas” (informação verbal, 2020)16.

Sua proposta em arte-educação voltada às artes cênicas começa a ser gestada em um dos momentos mais truculentos da história do Brasil, durante a ditadura militar (1964 - 1985), em que o autoritarismo e o controle rígido das ações são constantes, impedimentos brutalmente sufocantes com relação às experiencias que objetivavam o desenvolvimento emancipatório, seja no ensino formal ou não-formal.

Devido à perseguição e vigilância no contexto político e ideológico, o trabalho artístico e educativo de Joana deste período foi marcado pelo arrojo poético, ético e estético de propostas que buscavam dar forma à busca por autonomia e emancipação dos atuantes e possíveis espectadores, um modo de propiciar às pessoas reconhecerem e intervirem na realidade.

Em trecho do livro Pega Teatro (2017a), Joana afirma que era preciso 
encontrar alguma ferramenta para resistir ao que estava acontecendo no Brasil durante a ditadura militar. Joana enveredou para o Teatro pela necessidade de buscar uma expressão para maior inserção social, e a inspiração de Paulo Freire ofereceu uma perspectiva da educação como liberdade, essencial na luta contra as opressões ${ }^{17}$.

Em muitas das experiências narradas sobre as propostas feitas neste período, é possível constatar o despertar, nos atuantes e nela, de uma consciência do próprio lugar que ocupava na sociedade. Por diversas vezes Joana relata como questionamentos surgiam durante a realização dos jogos, e como buscavam respostas no jogo, e como também utilizaram essa estratégia para denunciar e reivindicar.

As experiências com 25 operários e operárias, em um projeto de TeatroEducação na Vila Zaíra, na cidade de Mauá-SP, a convite do sociólogo Herbert de Souza, deixa clara essa potencialidade da proposta de ensino de Joana. Durante o processo, o contexto social de ausências de políticas públicas na comunidade se revela, e tornam-se temas para o jogo. Neste jogar, dramatizar para refletir sobre a necessidade de telefones públicos e de um posto de saúde se materializou como ação reivindicatória.

No processo de apreensão da linguagem dramática, a sociedade se revela, tendo o nosso atuante como sujeito. Não nos interessa o espetáculo como único resultado a ser conquistado, capaz de, por si só, justificar e legitimar nosso trabalho de arte-educação popular. Mais do que o espetáculo, é o processo a chave de nossa intervenção, que considero como a participação de um educador-artista da classe dominante, não para fabricar com o povo uma arte popular, mas para descobrir com ele a sua expressão e a sua capacidade de comunicar os conteúdos de sua realidade (Lopes, 2017a, p.90).

Aparentemente, neste processo foi encontrada uma solução estética similar aos procedimentos do Teatro do Oprimido do brasileiro Augusto Boal ou ainda das Peças Didáticas do alemão Bertolt Brecht. Porém, no caso mencionado acima, não

7 Veja-se link para a entrevista de Paulo Freire a Joana Lopes disponível em: http://acervo.paulofreire.org:8080/jspui/handle/7891/1882. Acesso em: 20 fev. 2020.

E ainda, da relação do ensino de Dança por Joana Lopes sob inspiração freiriana: https://www.metodista.br/revistas/revistas-metodista/index.php/ML/article/viewFile/1628/1634. Acesso em: 20 fev. 2020. 
foi uma proposição inicial de Joana Lopes o tema social ou as soluções estéticas, mas algo que brotou dos anseios e desejos de comunicação do próprios atuantes envolvidos em um processo de jogo dramático. Sendo assim, ainda que os resultados estéticos pudessem assemelhar-se à de outros grandes diretorespedagogos, Lopes preferia e ainda privilegia um processo ético-poético no qual o desejo de expressar e de comunicar dos atuantes possa tomar as mais variadas formas estéticas, e cuja ênfase não está na busca inicial por uma ou outra solução estética, mas pelos processos emancipatórios que encontrem nesta ou naquela vertente estética uma forma palpável de expressão e comunicação do grupo de atuantes envolvidos naquele processo singular.

A análise de Carminda André (2007) aproxima as práticas de Joana Lopes de uma ação cultural, porque o ensino de teatro cria um espaço e tempo de inquietação e provocação sobre coisas que são concretas. Contudo, existe a incerteza e a abertura à dos caminhos que serão percorridos entre a percepção da realidade, e possíveis desdobramentos deste reconhecimento e reflexão.

Segundo Teixeira Coelho, a ação cultural

é um processo com início claro e armado, mas sem fim especificado e, portanto, sem etapas ou estações intermediárias pelas quais se deva necessariamente passar - já que não há um ponto terminal ao qual se pretenda ou espere chegar. Na ação, o agente gera um processo, não um objeto (Coelho, 2001, p.13).

Criar processos de aprendizagem na perspectiva da ação cultural é proporcionar um espaço em que as pessoas possam desenvolver seus objetivos e fins, bem como seus modos de realizar os processos. É provocar a saída de seu ensimesmamento egóico e assim reconhecer a si mesmo, e conseguir perceber o que está ao seu redor, com uma percepção mais plena de quem reflete ativamente sobre a realidade e cujas ações possam ser materializações coerentes desta reflexão.

Porém, numa perspectiva mais contemporânea, revisitada por Cabrera (2016) o processo não resulta em um produto pré-definido de antemão, mas em um invento a ser construído por meio de uma construção coletiva. Como algo que vai sendo gestado ao longo de um tempo. A maturação da capacidade de 
metamorfose dos atuantes é a realização da experiência do sensível e social, que auxilia na compreensão da realidade, e impulsiona a transformação no contexto histórico em que os educandos se inserem, não mais como personagens esquemáticos de um texto dramático literário definido de antemão, mas como sujeitos históricos que constroem e reconstroem um texto cênico a partir do jogo dramático e das interações com sua realidade social.

A trajetória de Joana Lopes possui ainda outros episódios fundamentais para compreender suas escolhas e seus referenciais, na constituição de processos de ação cultural emancipatórios, o que se pode verificar por sua produção como diretora e pesquisadora na Unicamp e por sua produção bibliográfica mais atual. Porém, seguem ao longo da carreira certas obsessões como artista para que a arte esteja à serviço de um processo civilizatório, avesso à instauração da barbárie, e esteja à serviço das metas que libertam os indivíduos da alienação, e os transformam em sujeitos atuantes em suas próprias histórias, bem como, na construção de uma nova sociedade.

Refletir sobre esta trajetória profissional nos auxilia a compreender o panorama de práticas teatrais que foram desenvolvidas em um determinado contexto da História do ensino de teatro do Brasil, mais do que revelar traços de um fazer artístico, é levantar as potencialidades de uma forma de conceber e realizar o ensino do teatro por múltiplas abordagens, variadas éticas, poéticas e estéticas.

\section{Referências}

ANDRÉ, Carminda Mendes. O teatro pós-dramático na escola. Tese (Doutorado em Educação) - Faculdade de Educação, Universidade de São Paulo. São Paulo, 2007.

CABRERA, Theda. A maturação da capacidade de metamorfose no jogo mimicry. Urdimento, Florianópolis v.2, n.27, p.397-417, 2016. Disponível em: http://www.revistas.udesc.br/index.php/urdimento/article/view/8225. Acesso em: 22 fev. 2020.

CARDOSO, Elizabeth da P. Imprensa feminista brasileira pós-1964. Dissertação (Mestrado em Ciências da Comunicação) - Escola de Comunicações e Artes, Universidade de São Paulo, 2004. Disponível em: 
https://www.teses.usp.br/teses/disponiveis/27/27142/tde-17052004-

165710/publico/Imprensa_feminista_brasileira.pdf. Acesso em: 22 fev. 2020.

COELHO, Teixeira. O que é ação cultural. São Paulo: Brasiliense, 2001.

DEBÉRTOLIS, Karen Silvia. Brasil Mulher - Joana Lopes e a Imprensa Alternativa Feminista no Brasil. Dissertação (Mestrado em Comunicação e Informação) Faculdade de Biblioteconomia e Comunicação. Universidade Federal do Rio Grande do Sul, Porto Alegre, 2002.

LEITE, Rosalina de Santa Cruz. Brasil Mulher e Nós Mulheres: origens da imprensa feminista brasileira. Revista de Estudos Feministas. v. 11, n.1, Florianópolis, jan./jun., 2003. Disponível em: https://doi.org/10.1590/S0104-026X2003000100014. Acesso em: 13 jun. 2021.

LOPES, Joana. Pega Teatro. 1à.ed. C.T.E.P.: 1981.

LOPES, Joana. Pega Teatro. 2a ed. Campinas, SP: Papirus, 1989.

LOPES, Joana. O teatro antropomágico. Blog Artes Cênicas Integradas, 2008. Disponível em: http://artescenicasintegradas.blogspot.com/2008/09/o-teatroantropomgico-joana-lopes.html. Acesso em: 26 jan. 2021.

LOPES, Joana. Pega Teatro. 3. ed. Bragança Paulista - SP: Urutau, 264 p., $2017 a$. Disponível em: https://www.joanabizzottolopes.com/copia-ficha-tecnica. Acesso em: 20 ago. 2019.

LOPES, Joana. Arte ampliada. Web site. 2017b. Disponível em: www.joanabizzottolopes.com Acesso em: 28 jan. 2021.

MADUREIRA, José Rafael; YONASHIRO, Andreia Ferreira. Joana Lopes e a Coreodramaturgia: Diálogos entre o jogo dramático e a arte do movimento de Rudolf Laban. Revista Cena, Porto Alegre, no 32 p. 246-258 set./dez. 2020. Disponível em: https://seer.ufrgs.br/cena/article/view/104330. Acesso em: 26 jan. 2020.

OLIVEIRA, Roberto Cardoso. O trabalho do antropólogo: olhar, ouvir, escrever. In: O trabalho do antropólogo. 2.ed. São Paulo: UNESP/Paralelo 15, 2000.

PERCURSOS da Arte na Educação. Depoimento de Joana Lopes. 25’09". Disponível em: https://www.youtube.com/watch?v=-0Xh901LZ48\&t=237s. 2014. Acesso 21 abr. 2019.

PUPO, Maria Lúcia de Barros. Para desembaraçar os fios. In: Educação e realidade. São Paulo, vol. 30- pp.217-228- jul./ dez. 2005b

RYNGAERT, Jean-Pierre. O jogo dramático no meio escolar. Coimbra: Centelha, 1981. 
As reverberações de Pega Teatro, de Joana Lopes: Contribuições para uma pesquisa em teatro educação

RYNGAERT, Jean-Pierre. Jogar, representar: práticas dramáticas e formação. São Paulo: Cosac \& Naif, 2009.

Recebido em: 14/04/2021

Aprovado em: 21/06/2021 